\title{
Ecos da XXII Reunião Anual de Pesquisa Aplicada em Doença de Chagas e X Reunião Anual de Pesquisa Aplicada em Leishmanioses
}

\author{
Echoes from the $22^{\text {nd }}$ Annual Applied Research Meeting on Chagas Disease and the \\ $10^{\text {th }}$ Annual Applied Research Meeting on Leishmaniasis
}

\author{
Uberaba, MG - 27 a 29 de outubro de 2006
}

\author{
Luiz Fernando Junqueira Junior ${ }^{1}$
}

\begin{abstract}
RESUMO
A doença de Chagas e as leishmanioses são importantes condições que ainda afetam milhões de pessoas, com relevantes implicações médicas, sociais e econômicas. As reuniões anuais sobre doença de Chagas e leishmanioses são marcantes fóruns de discussão sobre novos achados acerca destas doenças, bem como de planejamento de estratégias de controle, que envolvem grande número de conceituados e de jovens pesquisadores. Assim, essas Reuniões devem continuar com todo vigor representando a luta contra tais doenças.
\end{abstract}

Palavras-chaves: Doença de Chagas. Leishmanioses. Reuniões anuais.

\section{ABSTRACT}

Chagas disease and leishmaniasis are important conditions that still affect millions of people, with significant medical, social and economic implications. The annual meetings on Chagas disease and leishmaniasis are outstanding forums for discussing new findings regarding different aspects of these diseases and for planning control strategies, which involve large numbers of young and senior researchers. Thus, such meetings must continue to vigorously represent the struggle against these diseases.

Key-words: Chagas disease. Leishmaniasis. Annual meetings.

Com pleno sucesso, concretizou-se mais uma versão da já tradicional Reunião Anual de Pesquisa Aplicada em Doença de Chagas e Leishmanioses, na tranqüila e hospitaleira Cidade de Uberaba, MG, em sua Faculdade de Medicina. De há muito consolidada pela qualidade, importância e regularidade das suas versões anteriores, a atual Reunião não só manteve estes paradigmas, como se destacou sobremaneira pela demonstração de vitalidade, vigor e entusiasmo contagiantes na continuidade do interesse pelo estudo da doença de Chagas e das leishmanioses.

Confirmando todas as expectativas, a Reunião foi exemplarmente bem organizada e coordenada, com incomum entusiasmo e competência, pelo Prof. Dalmo Correia, da Disciplina de Doenças Infecciosas e Parasitárias, da própria Faculdade de Medicina de Uberaba, com o apoio sempre imprescindível do Prof. Aluízio Prata. A sessão de abertura não poderia ter sido mais marcante, sensibilizando a todos, pela forma como ocorreu e pela justa homenagem póstuma, prestada com a singular propriedade de sempre pelo Prof. João Carlos Pinto Dias, à saudosa e inesquecível Prof $^{a}$ Vanize de Oliveira Macedo, merecedora de todas as honrarias pelo incomum trabalho dedicado à Medicina brasileira, em particular no campo das doenças infecto-parasitárias ${ }^{25}$.

Quanto à programação, merecem ser destacados o esmero com que foi preparada e sua qualidade temática, pela inclusão de grande diversidade de temas de interesse, sempre atual e de grande relevância, para ambas as doenças, apresentados por pesquisadores e professores do mais elevado conceito.

o Programa foi enriquecido pela realização de dois cursos, sete mesas-redondas, três simpósios, e apresentação de oito conferências, sete grandes temas convidados e 135 comunicações sob forma de pôsteres (73 sobre doença de Chagas e 62 sobre leishmanioses), bem como quatro reuniões e seis oficinas de trabalho ou de diretrizes sobre questões de alta relevância prática ou relacionadas a projetos de pesquisa

1. Laboratório Cardiovascular, Cardiologia, Área de Clínica Médica, Cardiologia da Faculdade de Medicina da Universidade de Brasília, Brasília, DF.

Endereço para correspondência: Prof. Luiz F. Junqueira Jr. Área de Clínica Médica, Cardiologia/FM/UnB, Campus Universitário, 70910-900 Brasília, DF.

e-mail: lfjunq@unb.br

Recebido para publicação em 16/11/2006

Aceito em 24/11/2006 
em andamento. Neste conjunto de atividades, foram totalizados 80 temas específicos sobre os mais diversos aspectos das doenças $^{1}$. Outro destaque foi o brilhantismo das diferentes modalidades de apresentações e das respectivas discussões desenvolvidas, altamente qualificadas pelo elevado nível científico e participativo dos convidados, palestrantes, autores de comunicações e ouvintes, em sessões repletas ou com número sempre significativo de assistentes. Também, chamaram a atenção a participação e o interesse de grande número de estudantes de graduação e de pós-graduação acompanhando seus professores e orientadores, da própria Faculdade de Medicina de Uberaba e de outras Faculdades do país.

Desnecessário é enfatizar a importância destas reuniões, para o amplo conhecimento e, em decorrência, para 0 controle e tratamento de duas grandes endemias nacionais, que interessam também outros países, as quais continuam vitimando milhares de desafortunados - a doença de Chagas e as leishmanioses. Diversas diretrizes e articulações políticas de combate a estas duas condições, muito do seu conhecimento parasitológico, patológico, clínico e funcional e das suas orientações terapêuticas, bem como múltiplas sugestões de novas pesquisas, nasceram e floresceram da série de reuniões até aqui realizadas. Certamente, muito ainda poderá resultar das futuras reuniões.

No caso da doença de Chagas, a OPAS/OMS declarou 0 Brasil livre da transmissão vetorial no dia 9 de junho de $2006^{4}$. Interrompeu-se a transmissão pelo seu principal agente - o Triatoma infestans, em quase todos os países do Cone Sul, bem como a transmissão transfusional sangüínea ${ }^{36}$. Mas a doença não deixou de existir, apesar do golpe sofrido. Enquanto persistirem o agente causal, os transmissores vetoriais alternativos e os reservatórios animais domésticos e silvestres, em associação com as condições sócio-epidemiológicas capazes de permitirem a infecção humana, ela sempre estará latente, potencialmente passível de recrudescimento. 0 agente causal certamente não desaparecerá da escala zoológica em tempo previsível. Outros triatomíneos transmissores, já em pequena escala, não foram eliminados, e estão prontos para assumir o lugar do transmissor dominante extinto. Os reservatórios animais, domésticos e silvestres, não são passíveis de extermínio. As precárias condições sociais, educacionais, higiênicas e econômicas de vida da população ainda parecem estar longe de serem abolidas ou aceitáveis.

Portanto, a vigilância contra a doença de Chagas não pode ser relaxada, pelo julgamento de que a questão se encontra resolvida pela interrupção de seu transmissor vetorial ${ }^{3}$. Também, a motivação para prosseguimento da sua compreensão, controle e tratamento não deve esmorecer, pois muito falta ainda para ser esclarecido e, até porque, a doença se constitui em nosologia universal, representando paradigma para o entendimento de diferentes condições fisiopatológicas e clínicas que lhe assemelham em diversos aspectos, em particular no campo da cardiologia. Felizmente, favoráveis a estas expectativas foram a elevada quantidade, a destacada qualidade e a grande diversidade das questões apresentadas e discutidas com entusiasmo e vivo interesse na recente Reunião.

De fato, o pensamento de que o controle da doença de Chagas deve persistir, não obstante seja um desafio, permanece presente na consciência dos responsáveis diretos. Da mesma forma, a motivação pelo estudo da doença segue forte, com avanços em todos os seus aspectos, demonstrada por dedicada plêiade de novos e jovens pesquisadores e interessados que já trabalham sob forma independente, ou em colaboração com seus entusiasmados mestres e orientadores experientes, que muito já contribuíram, para o que se conhece hoje, e continuam contribuindo com novos estudos sobre uma doença de abrangência continental que, apesar de ter sido identificada há quase um século, ainda continua vitimando milhares de pessoas. É alvissareiro, e muito gratificante, constatar que, a cada ano, novos grupos de pesquisa sobre diferentes aspectos da doença de Chagas se consolidam ou emergem altamente promissores.

A expectativa é de que o êxito plenamente alcançado pela Reunião recém-encerrada possa se repetir nas reuniões vindouras, para que o interesse pela doença de Chagas e pelas leishmanioses se mantenha sempre vivo e vigoroso, resultando em benefícios cada vez maiores para os milhões de indivíduos acometidos por ambas as condições, as quais permanecem como importantes desafios a exigir mais conhecimentos e soluções.

\section{REFERÊNCIAS BIBLIOGRÁFICAS}

1. Correia $F^{\circ} D$. (Coord) XXII Reunião de Pesquisa Aplicada em Doença de Chagas e X Reunião de Pesquisa Aplicada em Leishmanioses. Uberaba, MG. Revista da Sociedade Brasileira de Medicina Tropical 39 (Suplemento III), 2006.

2. Dias JC. Vanize Macedo: Cientista, Mestra e Cidadã. Revista de Patologia Tropical 35: 81-85, 2006.

3. Dias JC, Silveira AC, Schofield CJ. The impact of Chagas' disease control in Latin America: a review. Memórias do Instituto Oswaldo Cruz 97: 603612, 2002.

4. Ministério da Saúde. Nota técnica: Brasil recebe certificado internacional da interrupção da transmissão vetorial da Doença de Chagas pelo Triatoma infestans. Secretaria de Vigilância em Saúde, Brasília, 9 de junho de 2006.

5. Prata A. Vanize de Oliveira Macedo (1934-2006). Revista da Sociedade Brasileira de Medicina Tropical 39: 318-319, 2006.

6. Schofield CJ, Dias JC. The Southern Cone Iniciative against Chagas' disease. Advances in Parasitology 42: 1-27, 1999. 